\title{
"Being Free Like a Bird"-The Meaning of Being an Informal Caregiver for Persons with Dementia Who Are Receiving Day Care Services
}

\author{
Gunn Eva Solum Myren 1,2,3, Ingela Enmarker1,2, Ellen Saur ${ }^{4}$, Ove Hellzen ${ }^{3}$ \\ ${ }^{1}$ Centre for Care Research, Mid-Norway, Steinkjer, Norway \\ ${ }^{2}$ Faculty of Health Sciences, Nord-Trøndelag University College, Namsos, Norway \\ ${ }^{3}$ Department of Nursing Science, Mid-Sweden University, Sundsvall, Sweden \\ ${ }^{4}$ Department of Education, Norwegian University of Science and Technology, Trondheim, Norway \\ Email: gunn-eva.s.myren@hint.no
}

Received 19 January 2015; accepted 2 February 2015; published 6 February 2015

Copyright (C) 2015 by authors and Scientific Research Publishing Inc.

This work is licensed under the Creative Commons Attribution International License (CC BY). http://creativecommons.org/licenses/by/4.0/

(c) (i) Open Access

\begin{abstract}
Respite care in the form of day care is one of the several respite services that aims to provide temporary relief to informal caregivers from their responsibilities of caring for a person with dementia. The purpose of this study was to illuminate the meaning of being an informal caregiver for a person with dementia living at home and receiving day care services. Narrative interviews were conducted, and data were analyzed using the phenomenological hermeneutic method. Two main themes emerged: "Living with limitations in everyday life" and "Having a life besides being a caregiver". The comprehensive understanding suggested living with a person with dementia, changes and influences the informal caregiver's life through a set of new roles and a new way of living and thinking. The result is discussed in light of Goffman's analysis of the structures of social encounters from the perspective of the dramatic performance.
\end{abstract}

\section{Keywords}

Dementia, Informal Caregivers, Day Care Services, Phenomenological Hermeneutic, Goffman

\section{Introduction}

Dementia is a progressive condition, meaning that people affected will increasingly develop loss of function and,

How to cite this paper: Myren, G.E.S., Enmarker, I., Saur, E. and Hellzen, O. (2015) "Being Free Like a Bird" - The Meaning of Being an Informal Caregiver for Persons with Dementia Who Are Receiving Day Care Services. Open Journal of Nursing, 5, 109-119. http://dx.doi.org/10.4236/ojn.2015.52013 
in the end, be fully dependent on others [1]. At least half of those with dementia in Norway live at home [2]. Most people with dementia have at least one informal caregiver, usually a spouse/cohabitant or another relative, and persons with dementia are increasingly dependent on family caregivers to provide daily care and to maintain their dignity [3] [4]. Providing care to a person with dementia requires a caregiver's commitment to the person, often at the neglect of the caregiver's personal health and functioning [5]. Chumbler et al. (2006) found no difference in caregiver burden between adult children and spouses [6]. In general, closer kinship ties are associated with increased caregiving duties [7]. Caregiving reduces one's available discretionary time, social activities, and the freedom to make choices and decisions. The most-common unmet needs reported by both persons with dementia and informal caregivers are lack of company, psychological distress, and lack of daytime activities [8] [9]. To address this problem, respite care in the form of day care is one of the several respite services that aims to provide temporary relief to informal caregivers from their responsibilities of caring for a person with dementia [10]. In its national plan for dementia, the Norwegian government has established day care services for people with dementia as a focus area, and the aim of this care is to help persons with dementia stay at home for as long as possible [2]. Day care services offer activities directed toward environmental management, where one sets the focus on facilitating social, physical, and mental conditions in order to achieve optimal well-being, coping, and personal development [11]. Hence, day care services represent both respite care and a place where persons with dementia can experience a meaningful day [12] [13]. The American sociologist Erving Goffman described in his work "The Presentation of Self in Everyday life” [14], human behavior in the everyday life interactions. Goffman see the world as a stage, where we are both performers and audience for each other. Combining Goffman's expressions; frontstage and backstage, we might be able to understand better the meaning of being an informal caregiver living with a person with dementia, receiving day care services. Several quantitative studies examine day care services as a form of respite care for informal caregivers [15]-[17]. However, information about how day care services influence the informal caregiver's everyday life from a qualitative perspective is still limited. Therefore, the aim of this study was to illuminate the meaning of being an informal caregiver for a person with dementia living at home, receiving day care services.

\section{Method}

This was an inductive qualitative study where informal caregivers were interviewed about their experiences of receiving day care services for persons with dementia living at home. We used a phenomenological hermeneutic method, inspired by the philosopher Paul Ricœur, as described by Lindseth and Norberg (2004) [18]. The purpose of the phenomenological hermeneutic method is to interpret, i.e., explain and understand, the meanings of a phenomenon through the interpretation of interviews transcribed as text [19].

\subsection{Participants and Context}

Five informal caregivers were recruited, by a nurse specializing in dementia care in three municipalities in Middle Norway. The same nurse obtained the written consent. Three of the informal caregivers were women and two were men; three were spouses and two were cohabitants. The length of their marriages/cohabitation varied from 5 to 53 years. The initial diagnoses ranged from three to nine years prior to the study. The ages of the informal caregivers varied from 68 to 78 years; the ages of persons with dementias varied from 68 to 81 years. The informal caregivers have all received day care services for the person with dementia for the past four years. The amount of day care services varied from two to eight days per month.

\subsection{Narrative Interviews}

Data were collected through narrative interviews. Narrative interviews provide a systematic way to interpret people's live experiences [20]. The interviews were booked and conducted by the first author in May and June 2013. Each informal caregiver decided the date, location, and length of the interview. The length of the narrative interviews varied from 25 minutes to 83 minutes. To encourage narration, the interview started with a broad open-ended question: "Please tell me what the day care services mean for you." Further on, questions that clarified and explored their experiences with the day care services were asked as needed, such as "How did you feel then?" or "Can you tell me more about that?” The interviews were audiotaped and subsequently transcribed verbatim. Pitch, pauses, and emotions such as laughter, sadness, or tears were also transcribed in the text. Later, 
the interviews were read through while simultaneously listening to the tapes.

\subsection{Ethical Considerations}

Written informed consent was obtained initially; however, at each interview, the information was repeated and consent was again obtained orally. In all the interviews, the interviewer sought to establish a safe and gentle atmosphere by speaking to the respondents in a friendly and reassuring manner [21]. According to the informants' wishes, all five interviews were conducted at the homes of the informal caregivers. Permission for research was granted by the Norwegian Social Science Data Services (No. 31594), and carried out in accordance with the World Medical Association Declaration of Helsinki [22]. The nurses specializing in dementia care in the three municipalities also acted as emotional backup resources for the informal caregivers if they needed somebody to talk to after the interviews.

\subsection{Data Analysis}

The experience is private, but its meaning is public [19]. An experience cannot be transferred to another person, but what is transferred from one person to another is the meaning of the experience. The process of analysis is characterized by dialectical movements between understanding and explanation, between the whole and the parts of the text. This interpretation process involves therefore three phases: naïve understanding, structural analysis, and comprehensive understanding [18]. Naïve understanding is the first surface interpretation of the text as a whole and provides a direction for further analysis. During the naïve reading, we read the interview text separately several times. This reading was performed with as open-minded a perspective as possible [18]. In this way, all of the narratives were read from beginning to end. This first reading and preliminary understanding can be seen as pure guesswork [19]. Second, structural analysis was conducted to validate or invalidate the naïve understanding. Structural analysis is directed towards the structure of the text, where the text can be explained by identifying meaningful parts and patterns [18]. An example of the analysis is shown in Table 1.

In the structural analysis, the texts were divided into meaning units and condensed with the aim to preserve their essence [18]. Further on, the meaning units were compared with each other, and then arranged and sorted into meaningful connections and organized into themes and sub-themes. During this process, the themes were mirrored against the naïve understanding to validate this understanding. The data and the process of labeling and creating sub-themes and themes involved and were discussed with all authors. The structural analysis revealed two themes with four and three sub-themes as shown in Table 2.

The third phase, comprehensive understanding, is based on the authors' pre-understanding of the naïve reading, the structural analysis, and the theoretical frameworks, with the aim of gaining a deeper understanding of the text [18]. We chose to illustrate the sub-themes with core stories instead of quotations from the five informal caregivers. The creation of core stories, according to Emden (1998) [23], reduces full-length stories to shorter ones in order to assist the data analysis process. In this study, we have created core stories after the structural analyses, using meaning units as "mini core stories". With the meaning units from the five informal caregivers, we then created larger core stories to illustrate each sub-theme. Using core stories in this way, we could provide better insight into the informal caregiver's narratives and, at the same time, prevent the informal caregivers from being identified. We chose to construct the person with dementia in each core story as a male.

\section{Findings}

\subsection{Naïve Reading}

The narratives revealed that the informal caregivers struggle to balance their own needs for free time with their needs to care for the person with dementia. The informal caregivers experience challenges in the physical, psychological, and social dimensions: physical challenges as being administrators and giving practical help throughout the day; psychological challenges related to having a guilty conscience and experiencing the loss of their partners as they once were; and social challenges as a result of not being able to spend time with friends and/or experiencing a decrease in social life with friends. The days with day care services mean that the informal caregivers have a "legitimate" day off from their duties as caregivers, that is, "legitimate" in that they don't have to ask family members or others for help taking care of the person with dementia. Further on, 
Table 1. An example of the data analysis process.

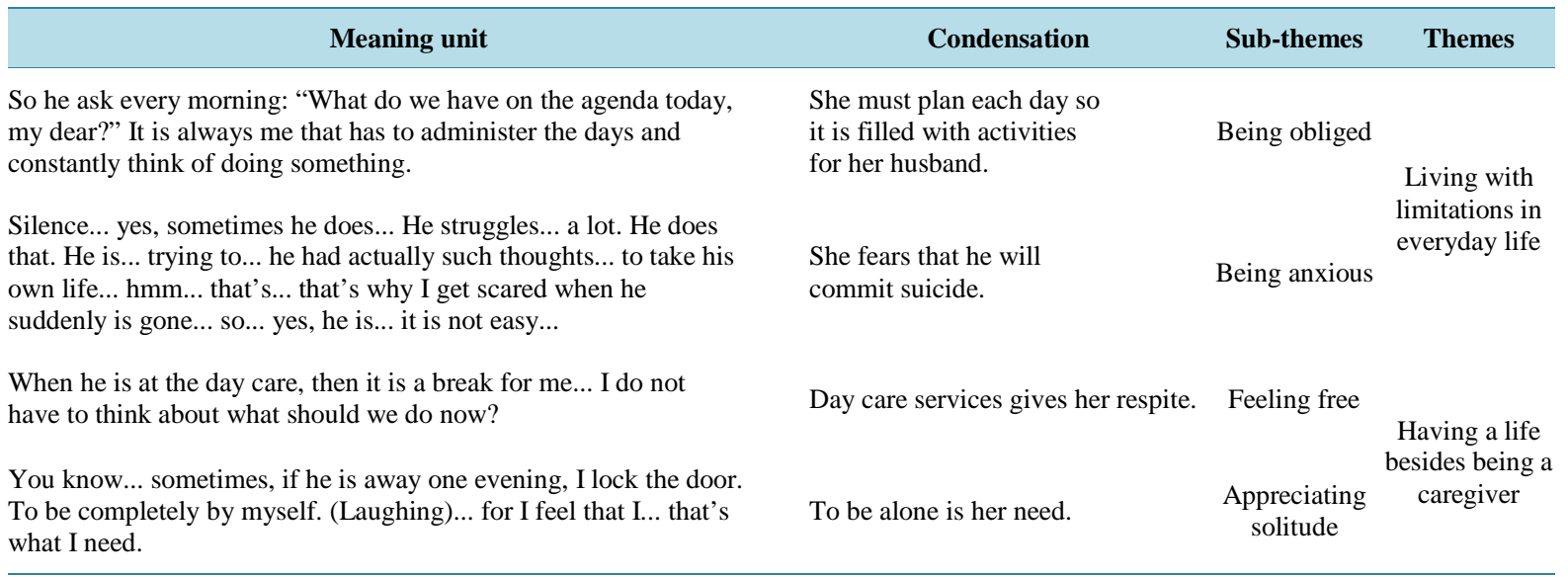

Table 2. Themes and sub-themes.

\begin{tabular}{ll}
\hline \multicolumn{1}{c}{ Theme } & \multicolumn{1}{c}{ Sub-theme } \\
\hline $\begin{array}{l}\text { Theme 1: } \\
\text { Living with limitations in everyday life }\end{array}$ & Being obliged \\
& Being confronted with singularity \\
& Being anxious \\
& Feeling lonely \\
& Feeling free \\
Theme 2: & Appreciating solitude \\
& Being seen \\
\hline
\end{tabular}

the informal caregivers gave a description of how they experienced the feeling of not having enough capacity to take care of the person with dementia and their uncertainty about asking for more help.

\subsection{Structural Analysis}

\subsubsection{Living with Limitations in Everyday Life}

As this first theme expresses, the informal caregivers in this study experience that they are living with limitations in everyday life. Four sub-themes with each core story describe these limitations.

\section{1) Being Obliged}

Being obliged meant being in a relationship with a person with dementia that always claimed the informal caregiver's attention in almost every situation where they were together. Being obliged meant, in other words, that the informal caregivers are in a dependent life situation. Some talked about the dependency in everyday life, such as the inability of the person with dementia to perform activities of daily life. They needed help to remember or practical help to perform activities of daily life such as showering, taking medication, dressing, and so on. Being obliged meant, in other words, having no real choices about their own spare time because if they, on rare occasions, went out, they always had a guilty conscience for leaving the person with dementia at home.

Core story: "He asks me, 'What do we have on the agenda today, my dear?' I have to plan every day for him and fill the days with activities we can do together. Sometimes I think I live as if I have Alzheimer's too... He is very dependent on me. He really is. I do not think he would have managed the activities of daily life if I wasn't here... No... I don't think so... I can feel that this way of living does not do me any good, either physically or mentally. He is 100 percent dependent on me. If we are going outside, I have to walk in the front. Either I hold my hand on his shoulder or just stay in front of him... I used to say that I have to act like a bell cow. Then he follows me... And if we are separated, if I do go meeting some friends, 
I constantly have a bad conscience. It feels like I am running away from home.”

It seems that being obliged takes energy away from the informal caregivers, and they restrain their owns need for space or time to take care of themselves. Being an informal caregiver and being obliged means having a 24/7 job.

\section{2) Being Confronted with Singularity}

Being confronted with singularity meant both meeting and having the unusual happen in everyday life. In spite of trying to hold onto and carry out a normal day, informal caregivers were confronted with singularity each day. Meeting or facing singularity could be about organizing the day or witnessing the changes in the partner's personality. The spouses and cohabitants mention these changes as experiencing that they are losing their partners. The informal caregivers also note a change in their own personalities, i.e., being more impatient or more easily irritated. The couples that have been married or lived together for several years had always been there for each other and had been each other's supporters during the years.

Core story: "I wake up every morning telling myself this day is just another normal day. I act as if it is a normal day, as it used to be, before the illness (dementia)... until the confrontation of the unusual that I meet every day. He thinks differently, and he is no longer the same person he used to be... You have to give concrete messages, and at the same time, you do it by yourself. You don't bother. If I pressure him to do things, or I say things in the wrong way, he becomes angry. I become more impatient; I can feel that. That is not normal! More tired also, and as [I become] more tired, the more impatient I become. That hurts.... Becoming more easily irritated and angry, that is not me. No... I have much lower patience now than before... It's a bit of a defeat to admit the need for more help. (Whispering)... You weigh well the advantages and the disadvantages... Asking for help... it's a threshold I have to cross over. One day... maybe a couple of months ago, he asked me, "Do you think I have become a burden for you?” I answered him directly (the wife is almost whispering), 'No, I don't think so at all, but we do have a challenge to face. We have. You have an illness giving us some challenges. The illness can be a burden for me, but not you. You are you!'

Noticing the partner's personality changing is a strong confrontation of singularity. Another unusual aspect of everyday life was experiencing the increase in caregiver burden as another confirmation of the singularity. Living with a person with dementia meant experiencing asking for any kind of help as difficult. In particular, the need for more respite care was hard to admit for the informal caregivers. Being confronted with singularity meant experiencing loss not only by losing a partner but also noticing changes in their own personalities. In spite of meeting the challenges of singularity in their everyday lives, the informal caregivers embraced small, everyday moments that made them feel well.

\section{3) Being Anxious}

Being anxious meant that the informal caregivers spent a large part of their days and nights worrying about the next day, the next night, or the future. The informal caregivers were anxious about the person with dementia getting out in the middle of the night or getting lost during walks or holiday trips. Noticing changes in their partners' personalities gave informal caregivers concerns about their partners' psychological health. Even the economic situation in the future was a source of worry for some of the informal caregivers.

Core story: "But he... yes, he may suddenly also disappear from home. Then he could have been taking the bicycle and be just gone... I do think that is a bit scary. He is not telling me, just leaving the house. I have tried to tell him that he has to let me know when he is leaving the house. Then I know where he is. I'm so anxious about him when he disappears. Then he suddenly, he came home. He doesn't understand my worries... He tries to... he has had these thoughts about suicide sometimes, and then, when he disappears... I'm so afraid... There is another kind of worry, lying in front of me, when I am thinking about losing the good economic situation we have now. When the day comes and he has to move to the institution, I can't spend money on my children or grandchild, travelling or doing thing like that anymore because he has been the one earning the money... I'm not looking forward to being a greedy and grumpy old woman.”

It appears that the informal caregivers take on different roles, such as being a guard or even a therapist, in their efforts to support and protect their partners. Being anxious about how or when something might occasionally happen placed the informal caregivers in a demanding life situation. They strive and struggle to cope with the situation, trying to maintain a normal life with daily duties, including the "expected" holiday trip. Being an- 
xious means, in other words, living with uncertainty and not knowing what is going to happen next.

\section{4) Feeling Lonely}

The feeling of loneliness was expressed by each one of the informal caregivers. Feeling lonely meant that the informal caregivers experienced having nobody to talk to, a decrease in their social life, and, in a way, being left behind by the person with dementia by losing a confidante. Some of them pointed out the silence in the house as a source of loneliness. The informal caregivers experienced a decrease in their social lives; their social lives changed, with friends and even some relatives withdrawing after learning about the dementia diagnosis.

Core story: "It is becoming so silent in the house. We have not had that much of a conversation before either, but I used to get an answer. We had been asking each other questions and told each other about how the day has turned out... but not any longer. It is so quiet. We can be in the house almost the whole morning without talking... so quiet. When our children come over, I used to sit down in the sofa over there (pointing at another sofa at the other end of the living room). Then the children say to me, 'You must come and sit with us, Mother.' I say to them, 'I just want to sit down here. I don't have to be involved in the conversation; I just want to sit here and listen.' You see, the chat lets me feel the life coming back to the house. I think it is so terrible to see that people we have been sociable with for many years now withdraw, and they are not visiting us anymore... I observed in our circle of friends, it is few now..., if any, who enquire about my husband any more. It is very painful to observe. Night and day I feel so sincerely alone. I can’t burden my children with that. Things and situations in everyday life... I can't tell them... I feel I have so much responsibility. And I feel so alone about the responsibilities.”

The informal caregivers are living with limitations that influence their social lives. First, by being in an obliged situation where they have to set aside their own needs for free time activities, and they also give less priority to visiting with friends and so on. Second, they experience a decrease in social life, with colleagues, neighbors, and other friends withdrawing. Feeling lonely meant having a feeling of being alone with the responsibilities and needs of administering to a person living with dementia.

\subsubsection{Having a Life besides Being a Caregiver}

The second theme is about how the informal caregivers experience their lives when their partners are attending day care services. Three sub-themes reveal what day care services mean for them in their everyday lives.

\section{1) Feeling Free}

Feeling free meant that the informal caregivers could do whatever they wanted to in a limited time while the person with dementia attended day care services. These few hours belong only to them; the informal caregivers, knowing that their partners were being taken good care of, have a meaningful day. Having this "time off”, gave the informal caregivers opportunities to do things they couldn't do otherwise, for example, socialize, going out and meeting friends, enjoying a cup of coffee and just sitting down, or taking a walk or a fishing trip without any worries.

Core story: "I feel very safe when he attends day care services. I totally relax, yes, and I know that he is in good hands and has a lot of other people around. I know that they are taking good care of him. When I know that he is in a safe environment, having a meaningful day, and I can dispose my own time, it feels so much better... They are very valuable for me, those days... so absolutely. To feel... that in the moment I have no responsibility, you really don't have that responsibility... It feels so good and makes me feel well. That day, when attends day care services, I can do whatever I want to do! They said (her children) that I can ask them for help at any time, but when I ask for help, they can't. Either there is work or something else they have to do at the time. I'm not bothering to ask them again. But when it comes to day care services and the two days a week, I don't have to ask. I can just leave the house and be free like a bird... When he is at day care, it gives me a break, a breathing space in my everyday life. It is very, very important for me. It makes me able to take care of him and this whole situation I think. It is my two little oases in everyday life.

Receiving day care services as respite care allowed the informal caregivers to have a legitimate day off from their duties as caregivers, legitimate in that they don't need to ask others to run errands for them or ask for help to look after the person with dementia. The day care services give them a true break, to do almost whatever they want to do in those valuable hours while their partners are attending day care services. Feeling free meant hav- 
ing a taste of no responsibility for a few hours.

\section{2) Appreciating Solitude}

The informal caregivers said that even there is not so many hours each day that they can do what they want, but still they appreciate every minute. Even though some of them express that they are feeling lonely, they also have a need to be completely alone, without any demands being made on them. Appreciating solitude means, in other words, that the informal caregivers are able to gain strength after meeting their own needs.

Core story: “I don’t have any schedule those days, no... I just feel that this is my day! Nobody makes demands on me. Remember that if I get so lucky that I have one evening by myself, I often lock the door. I don't want anyone to disturb me. I'm not ashamed of telling you that. That is my need. I don't want to have coffee with someone else or see or meet anybody. Just be alone, take a deep breath, and feel the strength building up without anybody around... I can also drive to our cabin and just shut everything out and just be at the place that I adore most of all. That's my need. Sometimes I dream of having a whole day or maybe two days alone at the cabin...Having time by myself makes me become more patient, and you know, we still have some good times together, like taking nice walks outside, along the river... and now, I can better see that we have to be willing to deal with things as they appear.”

The informal caregivers expressed solitude to be a necessary breathing space. They told about when their partners are attending day care services, they can recover mentally, gaining more spirit and force to continue caregiving. Although some of the persons with dementia had day care services only one day every other week, this day "off duty" as caregiver provided valuable hours to recover. In other words, appreciating solitude meant experiencing a breathing space.

\section{3) Being Seen}

Being seen meant that health personnel and other relatives, for that matter, supported the informal caregivers in different ways, i.e., gave them acknowledgement. When persons with dementia receive day care services, health personnel may offer transport to and from the day care location. In this way, day care staffs meet the informal caregivers regularly. The informal caregivers expressed that these meetings are valuable. They are afraid that they are exaggerating the symptoms of their partners' dementia, making the person appear sicker than they are. In addition, getting feedback from other relatives makes the caregiver feel he or she is being seen.

Core story: "The nurse at the day care asked me if I needed more respite care because she thought I had changed. One extra day was granted in a short time, and I felt that I am not alone in feeling that I am tired and exhausted. That feels good. Some days I feel like... how am I going to live through this day? In what way can I handle this day? But so... the formal caregivers noticed that I am exhausted and helped me out... The staff at the day care, you see, I feel safe... they catch my need in a very good way... They tell me to take care of myself... Sometimes I think inwardly— 'is it so obvious? Am I looking so worn and haggard?' For me, it is very important that he attends the day care because then the staff also can see his progress in the dementia. Yes, you know, it is almost conclusive because I am so afraid that I am overreacting and interpreting... and that I am wrong, but the staff at the day care can see it too... But I think my daughter noticed... and said, 'Mother, you need to start taking care of yourself, now.' It was so good to hear her telling me that."

It might seem like through being seen, the informal caregivers regain self-confidence. They are getting confirmation: "Yes, it is true that he has lost more functioning; he is actually getting worse." This verification from others on the partner's progress in dementia helps the informal caregiver to better cope with the situation. The feeling of being seen and letting others suggest that the informal caregivers should seek more help also helps the caregivers to do so. It seems like being seen means allowing others to see the true façade and thereby let others take some of the responsibility of caregiving.

\section{Comprehensive Understanding and Discussion}

The meaning of being an informal caregiver for a person with dementia living at home and receiving day care services was understood in this study through the use of two themes developed from the informal caregivers narratives: "Living with limitations in the everyday life" and "Having a life besides being an caregiver."

The life situation for an informal caregiver to a person with dementia living at home is demanding, and most 
of the time, the caregiver lives with limitations in everyday life. They are trying to cope with their life situation, playing a role, and not letting anyone know how they really feel about having and caring for a partner with dementia. In regard to facing singularity and the feeling of being obliged, informal caregivers experience a decrease in their social lives, with friends and relatives shadowing the area. The informal caregivers avoid seeking more respite care and trying to cope with the burden alone for as long as possible. This delay or hesitation to talk about their situation or ask for more help from both formal caregivers and other relatives may be seen as a strategy to avoid being seen as helpless. Living with limitations every day means, in other words, living with responsibilities and different emotions that make troubling days for informal caregivers.

However, the few hours when their partners attend day care services, the informal caregivers explore some breathing space, letting them have a life besides being a caregiver. In the few hours when their partners attend day care services, the informal caregivers step out of the roll as caregiver, experiencing being free to do whatever they want to do. They let the mask fall off, but first only in front of themselves by achieving solitude. By experiencing day care services as true and legitimate respite care, it seems like the informal caregivers become more motivated and encouraged to find meaning in their caregiving roles. Also the feeling of being seen contributes to giving the informal caregivers the strength to carry on and to continue caring for their partners.

The American sociologist Erving Goffman describes human behavior in the interactions of everyday life [14]. The analogy is that the world is a stage, where all are both performers and audience for each other. Trying to control the impression we make to others, information is exchanged to confirm identity. According to Goffman individuals achieve this through a "performance” which is defined as: “...All the activity of a given participant on a given occasion which serves to influence in any way any of the other participants” [14].

Hence, the balance between living with limitations in everyday life and having a life besides being a caregiver can be understood as a performance. It seems that informal caregivers play or archive different roles depending on where, when, and in front of whom they are performing. Goffman assumes roles as "enactments" of the social expectations attached to a social status, and he uses concepts from the world of the theater [24]. When the individual performs a role in relation to an audience (i.e., society), such as being an informal caregiver to a person with dementia, that role is played out on frontstage and the performance (the informal caregiver's behavior) is open to judgment by those who observe it. By taking on a mask or a facade, informal caregivers try to live up to their own expectation to handle and cope with their life situation and even expectations from the rest of society. Further, the backstage area is a place where the actors can discuss, polish, or refine their performance without revealing themselves to their audience. Backstage is also a place to relax, let the masks fall off, and step out of the role [14].

Living with a person with dementia meant that the informal caregivers had to spend all their time assisting their partners and planning or organizing the partners' lives. In other words, they are living in a dependent life situation with obligations. Being obliged is also in line with what Mace and Rabins (2006) refer to as one of the most-common feelings reported as informal caregivers, namely, that they feel they are devoting all their time to care and caregiving [25]. One focus area in the national plan for dementia in Norway is, as mention in the introduction, establishing more day care services for persons with dementia with the aim of helping them to remain at home for as long as possible [2]. Hence, it might seem that informal caregivers experience being obliged both as an inner responsibility driven by a desire to take care of their partners but also as an expectation from the rest of the family, community, and society. We might assume that there are underlying expectations from society that we should take care of our partners "for better or for worse." In terms of Goffman it seems that informal caregivers are not willing to perform as helpless but rather as independent caregivers [14]. Informal caregivers' feelings of being obliged to take care of their partners can be seen as an integrated part of the role of being an informal caregiver-a social role they are trying to fulfill perfectly, without any complaining.

A second factor that had an impact on the everyday limitations for the informal caregivers was confrontation with singularity. The confrontation with singularity might reinforce the informal caregiver's role frontstage, acting in line with expectations and his or her own self-demands while trying to hide the daily struggle from others. Backstage, i.e., at home behind closed doors, the informal caregivers might let their frustrations out by being grumpy and irritated. Still, they avoid seeking more help and try to cope on their own.

Goffman claims there tends to be a desire "to avoid a scene" when performing in front of an audience [14]. Backstage, which is mainly at home, informal caregivers can let out their frustrations and irritations and even initiate a confrontation with the person with dementia. This relaxation of one's personal "front" enables the performer to ignore the social rules of politeness and decorum. Once backstage, “...the performer can relax: he can 
drop his front, forgo speaking his lines, and step out of character” [14]. However, this backstage behavior seems to give informal caregivers a guilty conscience.

Backstage is not only a place for acting "incorrectly," but also a place to relax and recover [14]. By embracing small golden moments with the person with dementia, it seems that informal caregivers achieve motivation and inspiration to carry on in taking care of their partners.

Several studies point out how differences in personality explain both caregiving burdens and mental health among informal caregivers [26] [27]. These could involve emotional feelings, e.g., being anxious. In this study, we found that being anxious included the fear of losing a partner through suicide or, on a more abstract level, through his or her changing personality. It appears that not knowing what to expect in the progress of the dementia or coping with the changes in a partner's personality results in informal caregivers experiencing grief. This grief and these worries are difficult to share with others frontstage. Without having someone to talk to or to share their feelings about losing a partner, informal caregivers must cope with the grief related to the loss by themselves. By seeing this as a backstage behavior, it would appear that coping with this grief makes they feel more alone and even leads them to experience greater anxiety.

Being an informal caregiver to a person with dementia could mean being lonely [28]. In addition, social isolation is associated with depression [29]. From this perspective, it seems logical to assume that being anxious and feeling alone are part of the same topic. As informal caregivers are performing frontstage, there is no space, time, or room to cope with these emotions. Furthermore, the fear of letting the mask fall and failing to be perceived as a "good" caregiver might contribute to the informal caregiver's loneliness.

"Knowing that his audiences are capable of forming bad impressions of him, the individual may come to feel ashamed of a well-intentioned honest act merely because the context of its performance provides false conclusions concerning him" [14].

Therefore, it can be understood that the informal caregivers experience a feeling of being between the devil and the deep blue sea in their efforts to cope with their emotions and loneliness. In contrast, receiving day care services for their partners with dementia meant that informal caregivers could experience the feeling of being free to do whatever they wanted to do for some hours and enjoy having a breathing space. Experiencing being free and have some relief from the caregiver burden is crucial for the informal caregivers' opportunities to have a lifestyle with leisure or time for themselves [30]. Phillipson and Jones (2012) found that informal caregivers who use day care services tend to have accepted their own needs for breaks as legitimate [31]. Therefore, accepting the need for these true and legitimate breaks, informal caregivers can act frontstage in a more proud and self-confident way. The performance demonstrates that, as informal caregivers, by allowing themselves to have a life besides that of being a caregiver, they also distanced themselves from the caregiving identity. Having a legitimate day off from caregiving without having to ask or bother other relatives with questions about helping out reinforced informal caregivers' feelings of being free and contributed to allowing them to experience solitude. In this way, being an informal caregiver also give each of them the opportunity to choose between frontstage or backstage performances. Performing frontstage, with a proud attitude towards being an informal caregiver invites others to share their knowledge about being an informal caregiver with all the duties and responsibilities that are involved in that role. On the other hand, informal caregivers may prefer being backstage, seeking respite and recovery by achieving solitude in ways that their audience might find unacceptable [14]. By locking the door, ignoring visitors, just being selfish, and even crying about their feelings of being an informal caregiver, they could keep what they perceive to be unacceptable emotions and behaviors backstage. Goffman, said, "By invoking a backstage style, individuals can transform any region into a backstage" [14]. Hence, the backstage area could also be out in nature or at a cabin. This backstage region gives the informal caregivers opportunities to relax and just be, without any demands or responsibilities for the moment.

Furthermore, there will be other performers, when social roles are defined as rights and duties attached to a given status, such as that of being an informal caregiver [14]. On these occasions, formal caregivers will play those roles. It appears that the performance or the role played by informal caregivers changes when they know or trust the other person or persons somebody. The change in performance could also mean that the formal caregivers might be able to see through the informal caregiver's frontstage performance. Allowing themselves to be seen as "an informal caregiver" is, for some of them, crucial in order to receive more help such as respite care.

\section{Methodological Considerations}

This phenomenological hermeneutic study presents one of several possible interpretations [19]. Furthermore, in 
a narrative interview method, the interviewer is regarded as a co-creator of the text [20]. The results must therefore be judged in relation to the pre-understanding of the authors that: "Every way of seeing is also a way of not seeing” [32]. Qualitative studies do not seek to generalize [33]. Still, with only five caregivers as informants in this study, it was important for us to secure and maintain their anonymity. Hence, we chose to create core stories of the meaning units following the structural analysis. Further, in spite of having only five informal caregivers' narratives, this study contributes evidence that suggests that informal caregivers to persons with dementia need to be seen beyond their roles as caregivers. Clearly, more research is needed to validate and further expand these findings.

\section{Conclusion}

Living with a person with dementia changes and influences the informal caregiver's life through a set of new roles and a new way of living and thinking. Being an informal caregiver to a person with dementia means living a life with limitations - physical, social, and even psychological. These limitations reflect the informal caregivers' feelings of being frontstage, performing the role of caregiver without any complaining. The role includes the feeling of being in a dependent life situation, especially when experiencing confrontation with singularity in everyday life, as well as the feeling of loneliness with a decrease in social outlets and the experiences of being obliged to take care of their partners. In contrast, when the person with dementia attends day care services, informal caregivers gain opportunities to enjoy a life beyond that of being a caregiver. Knowing that their partners are taken care of, the informal caregivers can choose to enter the frontstage or backstage-frontstage with selfconfidence, having the freedom to do what they want for some limited hours, or backstage, where they appreciate solitude and experience a sense of freedom from the caregiver burden and, as a result, gain new strength to carry on. By trusting and confiding in formal caregivers or significant others, informal caregivers seem to be better able to cope with the burdens and accept their needs for additional help to care for their partner with dementia.

\section{Acknowledgements}

The authors would like to thanks participants who made this study possible.

\section{References}

[1] Alzheimer’s Association (2012) 2012 Alzheimer's Disease Facts and Figures. Alzheimer's \& Dementia, 8, $131-168$. http://dx.doi.org/10.1016/j.jalz.2012.02.001

[2] (2007) Glemsk, men ikke glemt!: Om dagens situasjon og framtidas utfordringer for å styrke tjenestetilbudet til personer med demens. Sosial-og helsedirektoratet, Oslo, $122 \mathrm{p}$.

[3] Sousa, R., et al. (2010) The Contribution of Chronic Diseases to the Prevalence of Dependence among Older People in Latin America, China and India: A 10/66 Dementia Research Group Population-Based Survey. BMC Geriatrics, $10,53$. http://dx.doi.org/10.1186/1471-2318-10-53

[4] Chien, W.T. and Lee, I.Y.M. (2011) Randomized Controlled Trial of a Dementia Care Programme for Families of Home-Resided Older People with Dementia. Journal of Advanced Nursing, 67, 774-787. http://dx.doi.org/10.1111/j.1365-2648.2010.05537.x

[5] Mitrani, V.B., et al. (2006) The Role of Family Functioning in the Stress Process of Dementia Caregivers: A Structural Family Framework. The Gerontologist, 46, 97-105. http://dx.doi.org/10.1093/geront/46.1.97

[6] Chumbler, N.R., Grimm, J.W., Cody, M. and Beck, C. (2003) Gender, Kinship and Caregiver Burden: The Case of Community Dwelling Memory Impaired Seniors. International Journal of Geriatric Psychiatry, 18, 722-732. http://dx.doi.org/10.1002/gps.912

[7] Andrén, S. and Elmståhl, S. (2008) The Relationship between Caregiver Burden, Caregivers’ Perceived Health and Their Sense of Coherence in Caring for Elders with Dementia. Journal of Clinical Nursing, 17, 790-799. http://dx.doi.org/10.1111/j.1365-2702.2007.02066.x

[8] van der Roest, H.G., et al. (2009) What Do Community-Dwelling People with Dementia Need? A Survey of Those Who Are Known to Care and Welfare Services. International Psychogeriatrics, 21, 949-965. http://dx.doi.org/10.1017/S1041610209990147

[9] Miranda-Castillo, C., Woods, B. and Orrell, M. (2013) The Needs of People with Dementia Living at Home from User, Caregiver and Professional Perspectives: A Cross-Sectional Survey. BMC Health Services Research, 13, 43. 
http://dx.doi.org/10.1186/1472-6963-13-43

[10] Durand, M., Jamesb, A., Ravishankara, A., Bamraha, J.S. and Purandare, N.B. (2009) Domiciliary and Day Care Services: Why Do People with Dementia Refuse? Aging \& Mental Health, 13, 414-419. http://dx.doi.org/10.1080/13607860902879318

[11] Smebye, K.L. and Rokstad, A.M.M. (2008) Personer med demens: Møte og samhandling. Akribe, Oslo.

[12] Gústafsdóttir, M. (2011) Beneficial Care Approaches in Specialized Daycare Units for Persons with Dementia. American Journal of Alzheimer's Disease and Other Dementias, 26, 240-246. http://dx.doi.org/10.1177/1533317511402315

[13] Solum Myren, G.E., Enmarker, I., Saur, E. and Hellzen, O. (2013) Relatives’ Experiences of Everyday Life When Receiving Day Care Services for Persons with Dementia Living at Home: "It's Good for Her and Its Good for Us”. Health, 5, 1227-1235. http://dx.doi.org/10.4236/health.2013.58166

[14] Goffman, E. (1959) The Presentation of Self in Everyday Life. Doubleday Anchor Books, Doubleday, Garden City.

[15] Arai, Y., Kumamoto, K., Washio, M., Ueda, T., Miura, H. and Kudo, K. (2004) Factors Related to Feelings of Burden among Caregivers Looking after Impaired Elderly in Japan under the Long-Term Insurance System. Psychiatry and Clinical Neurosciences, 58, 396-402. http://dx.doi.org/10.1111/j.1440-1819.2004.01274.x

[16] Mossello, E., et al. (2008) Day Care for Older Dementia Patients: Favorable Effects on Behavioral and Psychological Symptoms and Caregiver Stress. International Journal Geriatric Psychiatry, 23, 1066-1072. http://dx.doi.org/10.1002/gps.2034

[17] Zarit, S.H., Kim, K., Femia, E.E., Almeida, D.M., Savla, J. and Molenaar, P.C.M. (2011) Effects of Adult Day Care on Daily Stress of Caregivers: A Within-Person Approach. The Journals of Gerontology, Series B: Psychological Sciences and Social Sciences, 66, 538-546. http://dx.doi.org/10.1093/geronb/gbr030

[18] Lindseth, A. and Norberg, A. (2004) A Phenomenological Hermeneutical Method for Researching Lived Experience. Scandinavian Journal of Caring Sciences, 18, 145-153. http://dx.doi.org/10.1111/j.1471-6712.2004.00258.x

[19] Ricoeur, P. (1976) Interpretation Theory: Discourse and the Surplus of Meaning. Texas Christian University Press, Fort Worth.

[20] Mishler, E.G. (1986) Research Interviewing: Context and Narrative. Harvard University Press, Cambridge.

[21] Oliver, P. (2010) The Student’s Guide to Research Ethics. Open University Press, Maidenhead, 180 p.

[22] World Medical Association Declaration of Helsinki (2002) Ethics Forum-Ethical Principles for Medical Research Involving Human Subjects. Journal of Postgraduate Medicine, 48.

[23] Emden, C. (1998) Conducting a Narrative Analysis. Collegian, 5, 34-39. http://dx.doi.org/10.1016/S1322-7696(08)60299-1

[24] Goffman, E. (1972) Encounters: Two Studies in the Sociology of Interaction. Penguin, Harmondsworth.

[25] Mace, N.L. (2006) The 36-Hour Day: A Family Guide to Caring for People with Alzheimer Disease, Other Dementias, and Memory Loss in Later Life. In: Rabins, P.V., Ed., A Johns Hopkins Press Health Book, 4th Edition. Johns Hopkins University Press, Baltimore.

[26] Gallagher-Thompson, D., et al. (2012) International Perspectives on Nonpharmacological Best Practices for Dementia Family Caregivers: A Review. Clinical Gerontologist, 35, 316-355. http://dx.doi.org/10.1080/07317115.2012.678190

[27] Nordtug, B., Krokstad, S. and Holen, A. (2011) Personality Features, Caring Burden and Mental Health of Cohabitants of Partners with Chronic Obstructive Pulmonary Disease or Dementia. Aging \& Mental Health, 15, 318-326. http://dx.doi.org/10.1080/13607863.2010.519319

[28] Moyle, W., Kellett, U., Ballantyne, A. and Gracia, N. (2011) Dementia and Loneliness: An Australian Perspective. Journal of Clinical Nursing, 20, 1445-1453. http://dx.doi.org/10.1111/j.1365-2702.2010.03549.x

[29] Beeson, R., Horton-Deutsch, S., Farran, C. and Neundorfer, M. (2000) Loneliness and Depression in Caregivers of Persons with Alzheimers's Disease or Related Disorders. Issues in Mental Health Nursing, 21, 779-806. http://dx.doi.org/10.1080/016128400750044279

[30] Robinson, A., et al. (2012) Seeking Respite: Issues around the Use of Day Respite Care for the Carers of People with Dementia. Ageing \& Society, 32,196-218. http://dx.doi.org/10.1017/S0144686X11000195

[31] Phillipson, L. and Jones, S.C. (2012) Use of Day Centers for Respite by Help-Seeking Caregivers of Individuals with Dementia. Journal of Gerontological Nursing, 38, 24-34. http://dx.doi.org/10.3928/00989134-20120307-05

[32] Silverman, D. (2000) Analyzing Talk and Texts. In: Denzin, N.K. and Lincoln, Y., Eds., Handbook of Qualitative Research, 2nd Edition. Sage, Thousand Oaks, 821-834

[33] Creswell, J.W. (200) Research Design: Qualitative, Quantitative, and Mixed Methods Approaches. 3rd Edition, Sage, Los Angeles. 
Scientific Research Publishing (SCIRP) is one of the largest Open Access journal publishers. It is currently publishing more than 200 open access, online, peer-reviewed journals covering a wide range of academic disciplines. SCIRP serves the worldwide academic communities and contributes to the progress and application of science with its publication.

Other selected journals from SCIRP are listed as below. Submit your manuscript to us via either submit@scirp.org or Online Submission Portal.
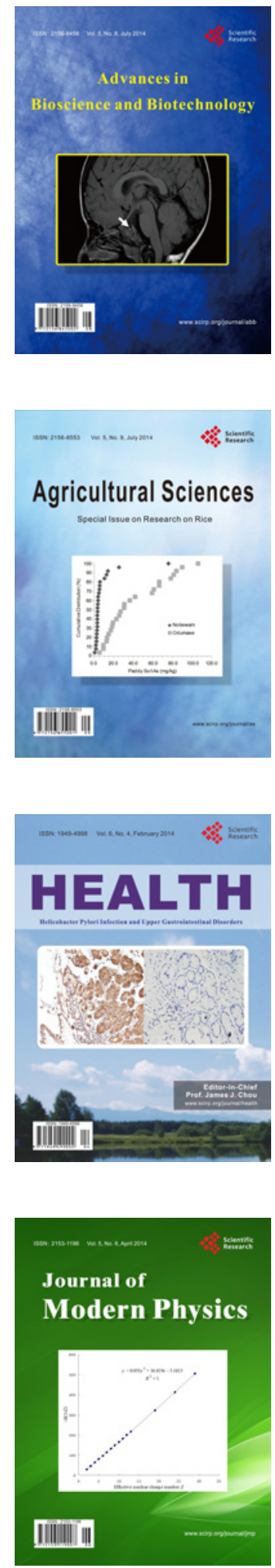
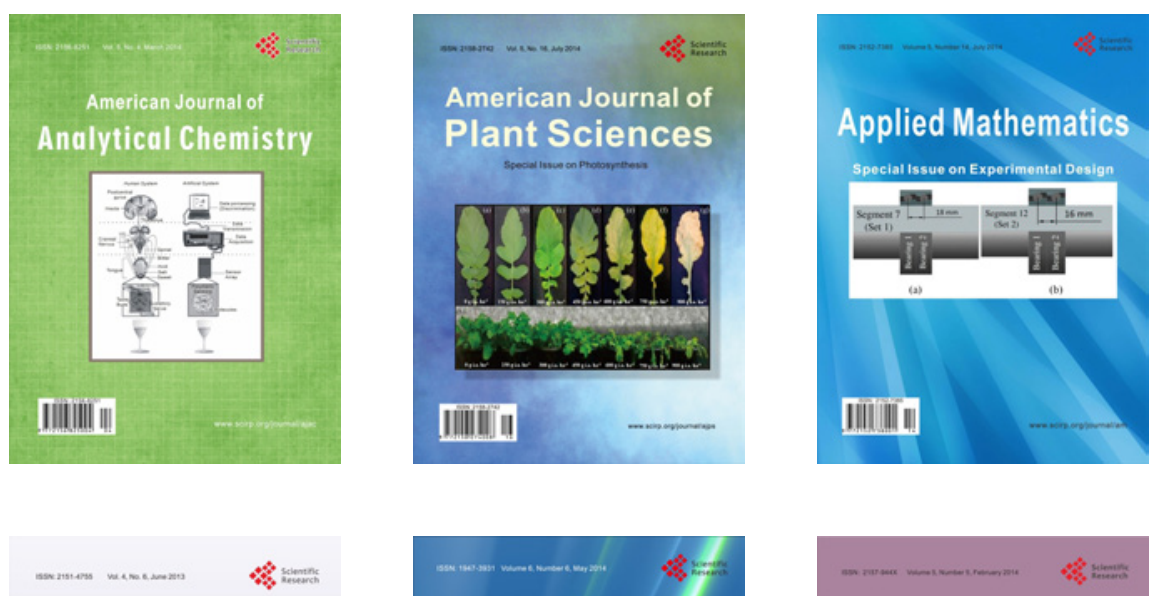

Creative Education
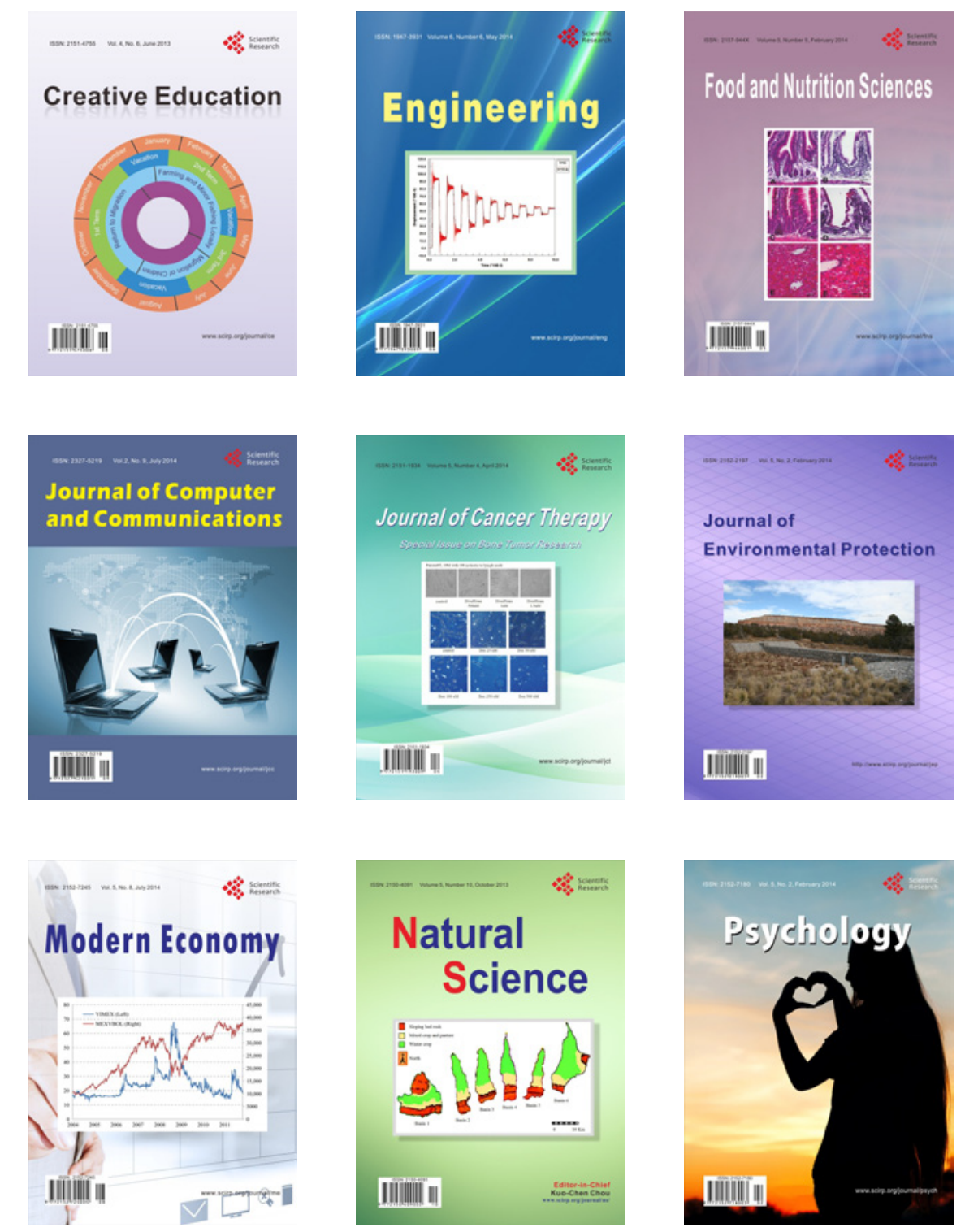